\title{
Agência de Bacia dos Rios Piracicaba, Capivari e Jundiaí
}

\author{
Maria Luiza Machado Granziera²
}

\section{Introdução}

O presente artigo tem por objetivo relatar as questões jurídicas enfrentadas no estudo que deu fundamento à definição do Consórcio Intermunicipal das Bacias dos Rios Piracicaba, Capivari e Jundiaí como Entidade Delegatária do Conselho Nacional de Recursos Hídricos (CNRH) para assumir funçōes de Agência de Água e celebrar contrato de gestão com a Agência Nacional de Águas (ANA) e futuramente com o Instituto Mineiro de Águas (IGAM).

$\mathrm{Na}$ linha de dar continuidade à implementação e consolidação das políticas públicas de recursos hídricos no País, retomou-se, em 2005, a discussão sobre a cobrança pelo uso da água nas Bacias Hidrográficas dos Rios Piracicaba, Capivari e Jundiaí, que abrangem os Estados de São Paulo e Minas Gerais. Um dos desafios enfrentados consistiu na definição do modelo jurídico-institucional da Agência de Água, buscando compatibilidades entre as normas federais sobre os recursos hídricos de domínio da União e as leis dos Estados de São Paulo e Minas Gerais. Essas normas prevêem a criação de Agências de Bacia, porém de modo não idêntico.

Além de desigualdades no conteúdo das normas legais, a cobrança pelo uso de recursos hídricos encontrava-se em fases distintas: já implementada em nível federal, no Estado de São Paulo estava em discussão o projeto de lei que resul-

1 Este artigo refere-se ao estudo elaborado para o Consórcio Intermunicipal das Bacias Hidrográficas dos Rios Piracicaba, Capivari e Jundiaí, com vistas a apoiar a decisão acerca do modelo institucional da Agência das Bacias Hidrográficas dos Rios Piracicaba, Capivari e Jundiaí, pelos órgãos e instituições componentes do Sistema de Gerenciamento de Recursos Hídricos.

2 Advogada em São Paulo, Mestre e Doutora em Direito pela Universidade de São Paulo, Professora Doutora do Curso de Mestrado em Direito Ambiental da Universidade Católica de Santos (UNISANTOS), autora do livro Direito de águas: disciplina jurídica das águas doces. 3. ed. São Paulo: Atlas, 2006. 
tou na Lei $\mathrm{n}^{0} 12.183$, de 29/12/05, regulamentada pelo Decreto $\mathrm{n}^{0} 50.667$, de 30/3/06. Em Minas Gerais, o Decreto n 44.046, de 13/6/05, já regulamentava a cobrança pelo uso de recursos hídricos de domínio do Estado, também em implementação.

Conceitualmente, a premissa do estudo foi a instituição de uma entidade única para os corpos hídricos de domínio da União, São Paulo e Minas Gerais, com vistas a garantir a sustentabilidade financeira e institucional e evitar a duplicação de esforços e despesas. Naturalmente, o modelo deveria ser compatível com as normas legais vigentes, assegurando sua sustentabilidade jurídica.

Compete à Agência de Água atuar de modo integrado em todos os aspectos técnicos relativos às bacias hidrográficas. Todavia, a gestão financeira só pode ocorrer em contas separadas da União e dos Estados de São Paulo e Minas Gerais, na medida em que os recursos da cobrança, de natureza pública, pois constituem preço público pelo uso de bens públicos, devem ser geridos e aplicados de acordo com o titular do domínio dos mesmos.

Cabe ressaltar que a Agência não deve exercer, em hipótese alguma, poder de polícia em matéria de recursos hídricos, atividade da Administração Pública que limita o exercício dos direitos individuais em benefício do interesse público e que contempla, no caso das águas, a regulamentação, a concessão de outorgas do direito de uso de recursos hídricos, a fiscalização e a aplicação de penalidades. Tais funções permanecem sob a competência dos órgãos e entidades de controle, em nada alterando o sistema vigente.

A partir da análise das figuras jurídicas do ordenamento jurídico pátrio, passíveis de assumir as atividades inerentes a uma Agência de Bacia, e das normas legais em vigor sobre Agências, seja em âmbito federal, seja em sede dos Estados de São Paulo e de Minas Gerais, cabia propor o modelo julgado mais conveniente, isto é, com maior probabilidade de sustentar-se legal, financeira e institucionalmente.

Colocadas as bases do estudo, e tendo em vista que as Bacias Hidrográficas dos Rios Piracicaba, Capivari e Jundiaí se destacam no que se refere à gestão dos recursos hídricos, cabe tecer o cenário jurídico e institucional de implantação da Agência de Água.

\section{Cenário jurídico e institucional das bacias hidrográficas dos Rios Piracicaba, Capivari e Jundiaí}

As bacias hidrográficas dos Rios Piracicaba, Capivari e Jundiaí possuem $15.320 \mathrm{~km}^{2}$ e abrangem o território de 79 municípios, sendo 71 no Estado de São Paulo e 5 no Estado de Minas Gerais. A regiāo é altamente desenvolvida, respondendo por mais de $7 \%$ do PIB brasileiro, configurando o segundo pólo industrial 
do País. Na porção central dessas bacias encontra-se a Região Metropolitana de Campinas, criada em 2000.

A região é pioneira em ações de gerenciamento de recursos hídricos, sobretudo pelo fato de ter atingido, já na década de 70 , níveis de poluição e escassez alarmantes, com riscos às atividades econômicas, ao meio ambiente e à própria saúde pública. Nesse cenário, o Decreto de São Paulo nº 28.489, de 9/6/88, declarou a Bacia Hidrográfica do Rio Piracicaba crítica e modelo de gestão de recursos hídricos.

A falta de tratamento de esgotos domésticos e efluentes industriais, assim como os resíduos agrícolas, como o vinhoto - resíduo da cultura da cana-de-açúcar - causou, ao longo do tempo, grandes dificuldades no abastecimento urbano, pois muitos pontos de captação encontravam-se próximos dos pontos de despejos, pela própria localização das sedes dos Municípios, cuja expansão diminuiu as distâncias anteriormente existentes.

A situação agravou-se principalmente pelo aumento da população e das atividades econômicas na região. Em face dos conflitos pelo uso da água e pela recuperação do meio ambiente, muitas medidas foram tomadas, seja na área pública, seja no setor privado.

Além da busca de novas tecnologias, focadas principalmente no reuso da água, experiências no campo institucional foram implantadas, tendo em vista o forte comprometimento da sociedade civil com essa questão.

Das associações civis instituídas, com finalidades voltadas aos recursos hídricos, destaca-se o Consórcio Intermunicipal das Bacias dos Rios Piracicaba, Capivari e Jundiaí. Fundado em outubro de 1989 , seu objetivo é a recuperaçāo de mananciais e o desenvolvimento sustentável na região.

Participam dessa associação civil sem fins lucrativos 42 municípios e 36 empresas, públicas e privadas, que repassam ao Consórcio recursos financeiros, destinados tanto ao custeio da instituição como à execução de projetos voltados às finalidades do Consórcio. Como entidade de direito privado, é apta para habilitar-se à obtenção de recursos do Fundo Estadual de Recursos Hídricos (FEHIDRO), ${ }^{3}$ atualmente advindos da compensação financeira pelo uso de recursos hídricos para a geração de energia elétrica.

No âmbito dos Sistemas de Gerenciamento de Recursos Hídricos, na bacia hidrográfica em tela foram implantados dois comitês. O Comitê das Bacias dos Rios Piracicaba, Capivari e Jundiaí (CBH-PCJ), criado pela Lei paulista $\mathrm{n}^{\circ} 7.663$, de 30/12/91, e instalado em novembro de 1993, é o órgão do Estado que con-

\footnotetext{
3 Por força do disposto na Lei $n^{\circ} 10.843$, de 5/7/01, que inseriu o art. 37-A na Lei $n^{0} 7.663 / 91$, é permitido às entidades privadas, sem finalidades lucrativas, usuárias ou não de recursos hídricos, com constituição definitiva há pelo menos quatro anos, que tenham por finalidade a proteção do meio ambiente ou recursos hídricos com atuação comprovada no âmbito do Estado ou na Unidade de Gerenciamento de Recursos Hídricos (UGRHIs), habilitar-se à obtenção de recursos do FEHIDRO.
} 
grega representantes do Estado (1/3), Municípios (1/3) e sociedade civil (1/3), compreendendo esse último segmento as ONGs, as universidades, as associações técnicas voltadas a recursos hídricos e usuários.

Faz parte da estrutura definida pela Política Estadual de Recursos Hídricos, já totalmente implantada e em funcionamento no Estado de São Paulo, no que tange aos comitês de bacia hidrográfica e ao Fundo Estadual de Recursos Hídricos (FEHIDRO), em que serão canalizados os recursos da cobrança pelo uso da água, quando de sua efetiva implantação no Estado de São Paulo.

O outro comitê (PCJ Federal) instalado na bacia foi instituído pelo Decreto Federal de 20/05/02, no âmbito das medidas de implementação da Política Nacional de Recursos Hídricos - Lei nº 9.433, de 07/01//97, visando à sua integraçāo com a Política Estadual. Sua composição difere substancialmente da composição do PCJ estadual: $40 \%$ de usuários, $40 \%$ de Poder Público e $20 \%$ da sociedade civil.

A instituição do Comitê PCJ Federal teve por fundamento confirmar a prática do gerenciamento integrado, descentralizado e participativo na região, com o entrosamento entre os Estados de São Paulo e Minas Gerais e o Governo Federal, por intermédio da Agência Nacional de Águas (ANA). A implantação desse novo comitê em região onde se situam corpos hídricos de domínio da União e dos Estados baseia-se na integração e na negociação permanentes, inclusive com o desafio das diferentes composições em cada comitê.

Como forma de minimizar essas dificuldades, relativas ao domínio das águas e ao gerenciamento das bacias hidrográficas, os dois colegiados funcionam da forma mais articulada possível, considerando que ambos tratarão, em grande parte, de decisões sobre um mesmo território - as bacias hidrográficas que, não sendo bens, mas conceito geográfico, não se submetem a domínio.

O Comitê CBH - PCJ tem por área de atuação as bacias dos rios Piracicaba, Capivari e Jundiaí, excluídos os corpos de água de domínio do Estado de Minas Gerais e os rios de domínio da União e, conseqüentemente, a participação da Uniāo e de Minas Gerais. A área de atuação do Comitê PCJ Federal inclui os rios de domínio de Minas Gerais e os de domínio da União na bacia, em São Paulo e em Minas Gerais. Dele participam representantes do Estado de São Paulo, de Minas Gerais e da União.

Há uma intersecção entre as atividades de ambos os comitês, na qual coincidem as bases de decisão, para garantir um resultado harmônico na atuação de ambos os colegiados, em temas de interesse comum.

Nessa ordem de idéias, há assuntos específicos do Comitê CBH - PCJ, como, por exemplo, o valor da cobrança pelo uso dos recursos hídricos nos rios de domínio do Estado de São Paulo, e outros específicos do Comitê PCJ Federal, como as deliberações acerca do enquadramento dos rios de domínio da União da bacia. E há temas, como, por exemplo, os estudos sobre uso e ocupação do solo, que constituem matéria comum a ambos os comitês. Mesmo nos temas a cargo de 
cada comitê, não há como tratar distintamente as matérias, pois da harmonia das decisōes depende a continuidade do processo de gestão nas bacias hidrográficas.

O regimento interno do Comitê PCJ Federal foi elaborado para que se considere, nas suas decisōes, o Comitê Estadual CBH - PCJ, evitando-se paralelismos. Um dos caminhos foi buscar estabelecer, em ambos os comitês, e na medida do possível, em função das diferentes normas aplicáveis, os mesmos representantes, o que contribui para assegurar a convergência em ambas as casas. A coincidência em certas decisões é fundamental, pois, embora compostas por rios de domínio da União e de domínio dos Estados, as Bacias Hidrográficas dos Rios Piracicaba, Capivari e Jundiaí constituem um todo indivisível, reconhecido pela própria lei.

Um fator a mencionar, no que toca aos recursos hídricos da regiāo, consiste no conflito gerado pela outorga de direito de uso de recursos hídricos, concedida em 1974 pelo Ministério de Minas e Energia, à Companhia de Saneamento Básico do Estado de São Paulo (SABESP), correspondente ao direito de derivar até 33 $\mathrm{m}^{3} / \mathrm{s}$ dos rios Jaguari, Atibainha e Juqueri, no denominado Sistema Cantareira, visando ao abastecimento público na Região Metropolitana de São Paulo, pelo prazo de 30 (trinta) anos.

Tendo vencido o prazo dessa outorga em 2004, e a reclamação das Bacias do Piracicaba, Capivari e Jundiaí, por mais volume de água, ocorreu uma longa negociação entre os órgãos e entidades competentes para a gestão de recursos hídricos, culminando em um acordo para a operação dos reservatórios Jaguari-Jacareí e Cachoeira do Atibainha, localizados na Bacia do Rio Piracicaba, pertencentes ao Sistema Cantareira da SABESP, objeto da Resolução Conjunta ANA/DAEE $n^{\circ} 428$, de 04/08/04, e alteraçōes posteriores.

Esse ato estabeleceu, também, a delegação, pela Agência Nacional de Águas (ANA) ao Departamento Estadual de Águas e Energia Elétrica (DAEE) e ao Instituto Mineiro de Gestão das Águas (IGAM), da competência sobre as outorgas preventivas e do direito de uso de recursos hídricos de domínio da Uniāo, nas bacias em apreço.

\section{Normas legais sobre recursos hídricos aplicáveis às agências}

Para a implantação da Agência das Bacias Hidrográficas dos Rios Piracicaba, Capivari e Jundiaí, fazia-se necessária a análise dos instrumentos legais que regem as Agências de Bacia/Agências de Água. ${ }^{4}$ Para tanto, cabe analisar as normas relativas a recursos hídricos de âmbito Federal e dos Estados de São Paulo e Minas Gerais.

\footnotetext{
4 A denominação "Agência de Bacia" é utilizada pelos Estados de São Paulo e Minas Gerais, em suas Políticas de Recursos Hídricos. A Política Nacional de Recursos Hídricos utiliza a expressão "Agência de Água".
} 


\section{I Lei Federal n09.433/97}

As Agências de Água integram o Sistema Nacional de Recursos Hídricos (Lei $\mathrm{n}^{0}$ 9.433/97, art. 33, V) e têm por finalidade exercer a função de secretaria executiva dos respectivos Comitês de Bacia Hidrográfica. A sua criação é autorizada pelo Conselho Nacional de Recursos Hídricos ou pelos Comitês Estaduais de Recursos Hídricos (art. 42, parágrafo único), mediante solicitação de um ou mais Comitês de Bacia Hidrográfica, condicionada "à prévia existência do respectivo ou respectivos Comitês de Bacia Hidrográfica e à viabilidade financeira assegurada pela cobrança do uso dos recursos hídricos em sua área de atuação" (art. 43).

Constituem competências das Agências de Água, sempre em sua área de atuação, entre outras, manter balanço atualizado da disponibilidade de recursos hídricos em sua área de atuação e o cadastro de usuários de recursos hídricos (art. 44). Mediante delegaçāo do outorgante, às Agências cabe cobrar pelo uso de recursos hídricos, efetuar a administração financeira dos recursos arrecadados com a cobrança e analisar e emitir pareceres sobre os projetos e obras a serem financiados com recursos gerados pela cobrança, encaminhando-os à instituição financeira responsável pela administração dos mesmos.

Além disso, são atribuições das Agências de Água gerenciar o Sistema de Informações sobre Recursos Hídricos, assim como promover os estudos necessários para a gestão dos mesmos, além de elaborar o Plano de Recursos Hídricos para apreciação do Comitê.

Compete ainda às Agências propor ao respectivo Comitê de Bacia Hidrográfica: 1. o enquadramento dos corpos de água nas classes de uso, para encaminhamento ao respectivo Conselho Nacional ou Conselhos Estaduais de Recursos Hídricos, de acordo com o domínio destes; 2. os valores a serem cobrados pelo uso dos recursos hídricos; 3. o plano de aplicação dos recursos arrecadados com a cobrança pelo uso dos recursos hídricos e 4 . o rateio de custo das obras de uso múltiplo, de interesse comum ou coletivo.

A Lei de Águas não estabelece a forma jurídica da Agência de Água. Todavia, tendo em vista a competência para efetuar a cobrança pelo uso de recursos hídricos, ainda que por delegação do outorgante, entende-se que a mesma não poderá constituir entidade de direito privado, na medida em que os recursos decorrentes da cobrança são de natureza pública e, portanto, só um ente público é competente para arrecadá-lo. No que se refere às demais competências, não há restrição para o seu exercício por pessoa jurídica de direito privado.

Cabe, aqui, um esclarecimento. A entidade de direito privado não pode arrecadar os recursos da cobrança pela razão apontada. Mas pode atuar em atividades acessórias e de apoio à cobrança, como a emissāo e envio de boletos de cobrança, sempre em nome do detentor do domínio dos recursos hídricos, mediante, aí sim, delegação do outorgante. 
Até o momento, não foi instituída nenhuma Agência de Água no País. ${ }^{5} \mathrm{Na}$ implantação da cobrança pelo uso de recursos hídricos de domínio da União, na Bacia do Rio Paraíba do Sul, ${ }^{6}$ concluiu-se pela necessidade não de uma Agência de Água, mas de um outro modelo institucional. A alternativa adotada foi a criação de uma associação civil sem fins lucrativos, denominada Associação Pró-Gestão das Águas da Bacia Hidrográfica do Rio Paraíba do Sul (AGEVAP), sendo que a Lei $n^{\circ}$ 10.881/04 estabeleceu o caminho para viabilizar as relaçōes jurídicas entre essa entidade e o Sistema Nacional de Recursos Hídricos.

\subsection{Organizações civis de recursos hídricos. Lei Federal n 10.881/04}

A Lei $n^{9}$ 10.881/04 teve por objetivo estabelecer uma alternativa legal para viabilizar a relação jurídica entre a Agência Nacional de Águas (ANA) e as entidades civis de recursos hídricos, relacionadas no art. 47 da Lei $n^{0} 9.433 / 97$, que pretendiam atuar como Agências de Água, mas que não encontravam no ordenamento jurídico então em vigor a base legal para essa atuação.

São organizações civis de recursos hídricos: 1. consórcios e associaçōes intermunicipais de bacias hidrográficas; 2 . associaçōes regionais, locais ou setoriais de usuários de recursos hídricos; 3 . organizações técnicas e de ensino e pesquisa com interesse na área de recursos hídricos; 4. organizaçōes não-governamentais com objetivos de defesa de interesses difusos e coletivos da sociedade; 5 . outras organizaçōes reconhecidas pelo Conselho Nacional ou pelos Conselhos Estaduais de Recursos Hídricos.

Nesse modelo, o Conselho Nacional de Recursos Hídricos (CNRH) delega a uma entidade civil de recursos hídricos, por meio de processo administrativo próprio, cujo ato final consiste na ediçāo de uma Resolução, ${ }^{7}$ competências inerentes às Agências de Água, salvo a cobrança pelo uso de recursos hídricos.

Como já mencionado, a competência para efetuar a cobrança pelo uso de recursos hídricos é exclusiva das Agências de Bacia criadas com essa finalidade específica ou, na sua ausência, da Agência Nacional de Águas (ANA), não podendo ser delegada às entidades ora em questão, por força do disposto no art. $2^{\circ}$, inciso VI, da Lei $\mathrm{n}^{\mathrm{0}} 10.881 / 04$.

A partir da delegação das funçōes de Agência de Água a uma entidade civil, é celebrado o contrato de gestão por prazo determinado com a Agência Nacional de

\footnotetext{
5 Algumas Unidades Administrativas Regionais da Agência Nacional de Águas foram implantadas, sem, contudo, configurar Agências de Água, mas apenas o fenômeno da desconcentração administrativa (Lei $\mathrm{n}^{\circ} 9.984 / 2000$, art. $3^{\circ}$, parágrafo único).

6 Primeira experiência de implantação da cobrança pelo uso de recursos hídricos no País.

7 Por meio da Resolução $\mathrm{n}^{9} 38$, de 26/03/04, o CNRH, com fundamento na MP $\mathrm{n}^{0} 165 / 04$, que se transformou na Lei $n^{\circ} 10.881 / 04$, delegou à AGEVAP competência para o exercício das funçōes de Agência de Água na Bacia Hidrográfica do Rio Paraíba do Sul por dois anos, prorrogáveis.
} 
Águas (ANA) e a entidade delegatária, que passa a assumir funçōes das Agências de Água relativas à gestāo de recursos hídricos de domínio da União, salvo, como já foi dito, para efetuar a cobrança.

Instituída uma Agência de Água, esta assume as competências estabelecidas pelos arts. 41 e 44 da Lei no ${ }^{0} .433 / 97$, encerrando-se, em conseqüência, o contrato de gestão referente à sua área de atuação.

\subsubsection{Natureza Jurídica do Contrato de Gestão na Lei nº $|0.88| / 04$}

Os contratos de gestão devem estabelecer os direitos, responsabilidades e obrigações das partes, destacando-se: 1. a especificação do programa de trabalho, a estipulação das metas a serem atingidas e os respectivos prazos de execução; 2 . a previsão expressa dos critérios objetivos de avaliação a serem utilizados, mediante indicadores de desempenho; 3 . a obrigação de a entidade delegatária apresentar à Agência Nacional de Águas (ANA) e ao respectivo Comitê de Bacia Hidrográfica, ao término de cada exercício, relatório sobre a execução do contrato de gestão, comparando as metas propostas com os resultados alcançados e 4 . prestação de contas dos gastos e receitas realizados.

De acordo com o disposto no $₫ 1^{\circ}$ do art. $2^{\circ}$, o termo de contrato deve ser submetido, após manifestação do respectivo ou respectivos Comitês de Bacia Hidrográfica, à aprovação do Ministro do Meio Ambiente.

Tendo em vista as dimensões do País e a diversidade de situações dos recursos hídricos e respectivas bacias hidrográficas nas várias regiōes, cabe à Agência Nacional de Águas (ANA) complementar a definiçāo do conteúdo e exigências a serem incluídas nos contratos de gestão de que seja signatária, observando-se as peculiaridades das respectivas bacias hidrográficas $\left(\$ 2^{\circ}\right)$.

Trata-se de uma forma de descentralização das atividades inerentes ao Poder Público ao particular, na mesma linha das Organizações Sociais (OS), regidas pela Lei federal $n^{0} 9.637 / 98$ e cujo instrumento obrigacional é o contrato de gestão, correspondente ao contrato de gestão objeto da Lei $\mathrm{n}^{\circ}$ 10.881/04, e das Organizações Civis de Interesse Público (OSCIP), regidas pela Lei federal nº 9.790/99, cujo instrumento básico consiste no Termo de Parceria.

Os mecanismos básicos do contrato são: 1. a fixação, pelo Poder Público, de metas a serem cumpridas pela entidade privada; 2 . o repasse de recursos públicos para a execução de atividades voltadas ao cumprimento das metas e 3. a fiscalização da execução dos objetivos estabelecidos.

No que se refere ao controle do contrato de gestão, a Agência Nacional de Águas (ANA), ao tomar conhecimento de qualquer irregularidade ou ilegalidade na utilização de recursos ou bens de origem pública pela entidade delegatária, dela dará ciência ao Tribunal de Contas da União, sob pena de responsabilidade solidária de seus dirigentes (art. $6^{\circ}$ ). 
Desde o início do processo de implantação da cobrança, em âmbito federal, duas questōes se colocavam: a primeira reportava-se ao risco de contingenciamento dos recursos já arrecadados e ainda não distribuídos e a segunda dizia respeito à necessidade de garantir-se que os valores fossem aplicados na bacia hidrográfica onde foram arrecadados. Essas duas questōes não estavam resolvidas na Política de Recursos Hídricos e geraram insegurança jurídica aos usuários-pagadores, pois sem essas garantias, não havia disposição para pagar pelo uso da água, o que criava um novo conflito.

O dispositivo que conferiu a necessária segurança jurídica e consistência ao fluxo financeiro da cobrança pelo uso de recursos hídricos encontra-se estabelecido no $\$ 1^{\circ}$ do art. $4^{\circ}$, que assegura à entidade delegatária as transferências da Agência Nacional de Águas (ANA) provenientes das receitas da cobrança pelos usos de recursos hídricos em rios de domínio da União, pela derivação ou captação de parcela da água existente em um corpo de água para consumo final, inclusive abastecimento público, ou insumo de processo produtivo, o lançamento em corpo de água de esgotos e demais resíduos líquidos ou gasosos, tratados ou não, com o fim de sua diluição, transporte ou disposição final, e outros usos que alterem o regime, a quantidade ou a qualidade da água existente em um corpo de água, que tenham sido arrecadadas na respectiva ou respectivas bacias hidrográficas.

Além disso, menciona-se expressamente nesse diploma legal, em seu $\mathbb{S} 3^{\circ}$, que se aplica a essas transferências o disposto no $\$ 2^{\circ}$ do art. $9^{\circ}$ da Lei Complementar $n^{\circ} 101$, de 4/5/2000 - Lei de Responsabilidade Fiscal, segundo o qual não serão objeto de limitação as despesas que constituam obrigaçōes constitucionais e legais do ente, inclusive aquelas destinadas ao pagamento do serviço da dívida, e as ressalvadas pela Lei de Diretrizes Orçamentárias.

No caso em tela, trata-se de obrigaçāo legal, pois, conforme exposto acima, o $\$ 1^{\circ}$ do art. $4^{\circ}$ da norma assegura expressamente à entidade delegatária as transferências da ANA, provenientes das receitas da cobrança por derivação ou captação, lançamento de esgotos e resíduos e outros usos que alterem o regime, a quantidade ou a qualidade dos recursos hídricos. Decorrendo de lei, ficam os valores relativos à cobrança livres de contingenciamento, vinculando-se à aplicação na bacia hidrográfica em que foram gerados. A partir da edição dessa norma, a cobrança pelo uso de recursos hídricos de domínio da União vem sendo efetuada sem maiores problemas, considerando-se que, no que toca à norma em vigor, a situação encontra-se resolvida.

Note-se que o modelo adotado na Lei $n^{\circ}$ 10.881/04 não privilegia uma instituição em si, mas um sistema contratual, em que a entidade delegatária assume a responsabilidade de alcançar as metas fixadas, prestando contas das atividades desenvolvidas e aplicação de valores à Agência Nacional de Águas. Se não alcançar as metas ou houver outro tipo de problema em sua atuação, elege-se outra entidade para assumir as atribuições da Agência. É uma forma de buscar a eficiência e o dinamismo na gestão dos recursos hídricos, no que se refere aos aspectos da cobrança. 


\subsection{São Paulo - Lei no $7.663 / 91$}

A Política Estadual de Recursos Hídricos, definida na Lei $n^{\circ} 7.663 / 91$, dispõe, em seu art. 29, que, nas bacias hidrográficas onde os problemas relacionados aos recursos hídricos assim o justificarem, por decisão do respectivo Comitê de Bacia Hidrográfica e aprovação do Conselho de Recursos Hídricos, poderá ser criada uma entidade jurídica, com estrutura administrativa e financeira própria, denominada Agência de Bacia, que exercerá as funções de secretaria executiva do Comitê de Bacia Hidrográfica.

As Agências de Bacias têm sua vinculação ao Estado e a organização administrativa, além de sua personalidade jurídica, disciplinadas na lei que autorizar sua criação $\left(\$ 2^{\circ}\right)$, vinculando-se esta ao início da cobrança pelo uso dos recursos hídricos.

A Lei $n^{\circ} 10.020$, de 03/07/98, em seu art. 5ํㅡ, alterou esse dispositivo, prevendo, excepcionalmente, a possibilidade de criação das Agências antes da implantação da cobrança, desde que os Municípios participantes e a sociedade civil custeiem as suas despesas. ${ }^{8}$

Entre as atribuições da Agência de Bacia, destacam-se: 1. a elaboração periódica do plano de bacia hidrográfica; 2. a elaboração de relatórios anuais sobre a "Situação dos Recursos Hidricos na Bacia Hidrográfica"; 3. o gerenciamento dos recursos financeiros do FEHIDRO pertinentes à bacia hidrográfica, gerados pela cobrança pelo uso da água e 4. a promoção, na bacia hidrográfica, da articulação entre os componentes do Sistema Estadual de Gerenciamento de recursos Hídricos (SIGRH), com os outros sistemas do Estado, o setor produtivo e a sociedade civil.

\subsection{Lei $n^{\circ} 10.020 / 98$}

Embora a Lei estadual $n^{\circ}$ 10.020/98 autorize, em seu art. $1^{\circ}$, o Executivo a participar da constituição de Fundaçōes Agências de Bacias Hidrográficas, essa norma trata, efetivamente, da formatação jurídica das Agências previstas no art. 29 da Lei n 7.663/91, em que é obrigatória a presença do Estado, por ser o detentor dos recursos hídricos objeto das ações da Agência de Bacia, inclusive no que toca à cobrança.

A autorização ali contida não significa que outra entidade possa exercer o papel de Agência, independentemente da participação do Estado. Apenas a Lei aproveita para autorizar, desde logo, o Executivo a participar da constituição de agências, o que significa que não serão necessárias leis autorizativas específicas para cada Agência.

8 Sob esse fundamento foi instituída a Agência de Bacia do Alto Tietê. 
O modelo adotado pelo Estado de São Paulo tem uma lógica diversa em relação ao modelo institucional adotado para as entidades delegatárias no âmbito federal, pois invoca uma instituição permanente, que recebe por lei a delegação de competências, não havendo contratualização entre o Estado e a Agência. Evidentemente, isso não significa que não haja a aplicação dos controles, previstos na lei, como ocorre para qualquer entidade que administre recursos públicos. Apenas não se estabelecem metas cujo cumprimento condicione a continuidade da Agência.

A instituição de uma Agência de Bacia, dirigida aos corpos de água superficiais e subterrâneos de domínio do Estado de São Paulo (art. $1^{\circ}$ ), depende da adesão de, no mínimo, 35\% dos Municípios interessados, abrangendo pelo menos $50 \%$ da população das Bacias (art. $2^{\circ}$ ).

É facultado ao Governo do Estado vetar a adoção de medidas que contrariem as diretrizes básicas dos planos e programas de gestão de recursos hídricos do Estado. Note-se que esse veto refere-se a hipóteses de descumprimento das diretrizes básicas dos planos e programas definidos. Não se trata de discricionariedade administrativa, mas do exercício do poder-dever inerente ao Estado, detentor do domínio dos recursos hídricos, responsável por sua guarda e proteção, de impedir o desvio da finalidade das entidades em apreço.

Nas Agências de Bacia, é assegurada a composição paritária tripartite entre o Estado, os Municípios e a sociedade civil, com direito a voz e voto de todos os seus membros, da mesma forma que são constituídos os Comitês de Bacia Hidrográfica e o Conselho Estadual de Recursos Hídricos (CRH). Não são distribuídos lucros, dividendos ou quaisquer outras vantagens aos seus instituidores, mantenedores ou dirigentes, empregando-se toda a renda no cumprimento das finalidades da Agência.

Constituem receita da Agência as transferências da Uniāo, Estados e Municípios destinadas ao seu custeio e à execução de planos e programas (art. $5^{\circ}, \mathrm{V}, a$ ). Esse dispositivo foi introduzido juntamente com outro que foi vetado, qual seja $o$ constante da alínea $b$, do mesmo inciso $V$, que estabelecia como receita da Agência os recursos provenientes da cobrança pelo uso de recursos hídricos. De acordo com as Razões de Veto, esses recursos constituem receita do Fundo Estadual de Recursos Hídricos (FEHIDRO). Alterar essa sistemática significaria contrariar os critérios e princípios estabelecidos na Lei $\mathrm{n}^{\circ}$ 7.663/91.

O que constitui receita da Agência são os recursos destinados ao seu custeio, limitado a $10 \%$ do total dos valores arrecadados com a cobrança, nos termos do art. ${ }^{\circ}$ da Lei. O produto de financiamentos destinados ao atendimento de serviços e obras constantes dos programas a serem executados não é repassado à Agência, mas administrado por ela, junto ao FEHIDRO e ao agente financeiro. Os recursos não se alocam na conta da Agência. Essa norma deverá ser objeto de revisão, quando da implantação da cobrança em corpos hídricos de domínio do Estado. 
São também receitas da Agência as aplicaçōes financeiras e outras operaçōes de crédito, doações de quaisquer outros recursos, públicos ou privados, e recursos provenientes de ajuda ou cooperação, nacional ou internacional, e de acordos intergovernamentais.

Os recursos da Agência são contabilizados em subcontas, específicas por Bacia Hidrográfica, do Fundo Estadual de Recursos Hídricos (FEHIDRO) e aplicados mediante empréstimo, com ou sem retorno, na forma aprovada pelo Comitê de Bacia e mantidos em conta bancária movimentada pela Agência. Ressalta-se também aqui que os recursos são administrados pela Agência, que fornecerá o parecer final sobre a compatibilidade dos projetos e o plano de aplicação aprovado pelo Comitê de Bacia Hidrográfica após a análise mais detalhada dos Agentes Técnicos.

A Agência é dirigida por três órgãos: Conselho Deliberativo, Diretoria e Conselho Fiscal. Os membros da Diretoria são remunerados e os membros do Conselho Deliberativo e do Conselho Fiscal exercem seus mandatos gratuitamente. O estatuto deve conter, também, mecanismos de autoconvocaçāo do Conselho Deliberativo.

O regime jurídico do pessoal da Agência é o da legislação trabalhista e a contratação de empregados, salvo para as funçōes de confiança definidas no Regulamento Interno, precedida de concurso público de provas e títulos, realizada diretamente por entidade especializada.

A Agência deve ter sede e foro em cidade da bacia hidrográfica, indicada pelo Comitê de Bacia, e suas competências reportam-se a: 1. apoio financeiro a planos, programas, serviços e obras aprovados pelo Comitê de Bacia; 2. capacitação de recursos humanos para o planejamento e gerenciamento de recursos hídricos; 3. educação ambiental e desenvolvimento tecnológico voltados ao uso racional dos recursos hídricos; 4. articulação dos participantes do Sistema Integrado de Gerenciamento de Recursos Hídricos (SIGRH) com os demais sistemas do Estado, com o setor produtivo, a sociedade civil, e com Estados vizinhos e seus Municípios pertencentes à Bacia Hidrográfica e a Uniāo.

No caso de a União vir a integrar a Agência e a delegar-lhe ou atribuir-lhe competência para atuar no campo das águas do seu domínio, o número de componentes do Conselho Deliberativo, da Diretoria e do Conselho Fiscal poderá ser alterado, inclusive quanto aos membros permanentes.

Nessa ordem de idéias, nada obsta que as Fundações Agências de Bacia, objeto da Lei no 10.020/98, recebam delegação do Conselho Nacional de Recursos Hídricos para assumir funções de Agência de Água frente aos recursos hídricos de domínio da União. O art. 47 da Lei $n^{\circ}$ 9.433/97 prevê, em seu inciso V, outras organizações reconhecidas pelo Conselho Nacional ou pelos Conselhos Estaduais de Recursos Hídricos, o que pode incluir as fundações de direito privado, como é o caso das Agências de Bacia. 
A partir de sua instituição, fica delegado à Agência o exercício das ações previstas no art. $4^{\circ}$, destacando-se: 1 . efetuar estudos, participar da gestão de recursos hídricos e elaborar o Plano de Recursos Hídricos da Bacia, em articulação com órgãos do Estado e Municípios; 2. aplicar recursos financeiros a fundo perdido; 3 analisar técnica e financeiramente os pedidos de investimentos de acordo com as prioridades e critérios estabelecidos pelo Comitê de Bacia; 4. fornecer subsídios à deliberação do Comitê sobre a cobrança pelo uso das águas; 5. administrar a subconta do FEHIDRO correspondente aos recursos da Bacia; 6 . efetuar a cobrança pela utilização dos recursos hídricos da Bacia de domínio do Estado; ${ }^{9}$ 7. gerenciar os recursos financeiros gerados por cobrança pelo uso da água; 8. elaborar relatórios anuais sobre a "Situação dos Recursos Hídricos das Bacias Hidrográficas" e 9. prestar apoio administrativo, técnico e financeiro ao funcionamento do Comitê de Bacia Hidrográfica.

O exercício do poder de polícia sobre a quantidade e qualidade das águas, e a outorga de licenças, autorizações, permissōes e concessōes administrativas, continuam a ser praticados pelos órgãos e pelas entidades estaduais competentes (art. $\left.6^{\circ}\right)$.

No que se refere à sustentabilidade financeira das Agências, podem ser despendidos até $10 \%$ dos recursos provenientes da cobrança pela utilização dos recursos hídricos em despesas de custeio e pessoal, observando-se o princípio organizacional de manter estruturas técnicas e administrativas de dimensões reduzidas, com prioridade para a descentralização (art. $3^{\circ}$, XXIII). Esse percentual pode diminuir à medida que os recursos da cobrança tornem-se expressivos, cabendo ao Conselho Deliberativo da Agência tal redução (Lei no 10.020/98, art. $8^{\circ}$ ).

A Agência sujeita-se ao controle do Tribunal de Contas do Estado (Lei no 10.020/98, art. $1^{0}$, parágrafo único). A Lei Complementar $n^{\circ} 837$, de 30/12/97, acrescentou o art. 30-A ao Decreto-lei Complementar $n^{0} 7$, de 6/11/69, determinando que não se aplica às Agências de Bacias, previstas no art. 29 da Lei $n^{0}$ 7.663/91, e sujeitas a regime especial, o citado Decreto-lei complementar, com exceção do disposto no art. $4^{\circ}$ e seu parágrafo único, nos arts. $5^{\circ}$ e $6^{\circ}$ e no art. $7^{q}$ e seus parágrafos.

Esses dispositivos estabelecem a vinculaçāo da Agência de Bacia a uma Secretaria de Estado ou órgão subordinado diretamente ao Governador (Decreto-lei Complementar $\mathrm{n}^{\circ} 7 / 69$, art. $4^{\circ}$ ), sendo que cabe à Secretaria de Estado a que a Agência estiver vinculada o controle de resultados de sua atuação, especialmente quanto ao atendimento das finalidades e objetivos institucionais e à sua situação administrativa (Decreto-lei Complementar no 7/69, art. 5).

Nos termos do art. 6º do Decreto-lei Complementar n⿳0 7/69, cabe à Secretaria de Estado dos Negócios da Fazenda, a posteriori, o controle de legitimidade das

\footnotetext{
9 Note-se que a lei paulista permite que uma entidade de direito privado da qual participe o Estado efetue a cobrança pelo uso da água.
} 
entidades descentralizadas, para o que devem estas manter sistema de registro e arquivamento, nos moldes fixados pelo órgão controlador, sem prejuízo do controle legal do Tribunal de Contas.

O controle de legitimidade é exercido por intermédio da Auditoria da Secretaria da Fazenda, à qual competirá verificar: 1. a legitimidade dos atos relativos à despesa, à receita e ao patrimônio, bem assim e especialmente os referentes a pessoal, material e transporte; 2 . os registros e documentos, contábeis ou não, demonstrativos ou comprobatórios de atividades e resultados; 3 . a existência de bens e valores e as condiçōes de sua guarda e utilização; 4. o cumprimento do cronograma de aplicação de recursos e 5 . o balanço anual e os balancetes mensais (Decreto-lei Complementar $n^{0} 7 / 69$, art. $7^{\circ}$ ).

Para esse controle, o Secretário da Fazenda poderá designar, para atuarem junto a cada entidade descentralizada, auditores cujas atribuições serão definidas em regulamento $\left(\$ 1^{\circ}\right)$. Todos os documentos serão obrigatoriamente submetidos aos auditores, ressalvados os casos a que se referir o regulamento mencionado no parágrafo anterior $\left(\$ 2^{\circ}\right)$. A Auditoria levará, incontinenti, qualquer irregularidade que vier a apurar ao conhecimento do Secretário da Fazenda, que a comunicará ao Secretário de Estado a que estiver vinculada a entidade descentralizada, o qual informará a respeito o Governador, relatando-lhe as providências tomadas. Quando não houver vinculação, a comunicação será feita diretamente ao Governador $\left(\$ 3^{\circ}\right)$.

A Lei no 10.020/98, em sua Disposição Transitória, artigo único, determina que o Poder Executivo tomará as medidas necessárias à participação do Estado, juntamente com os Municípios e a sociedade civil, na instituição da Fundação Agência das Bacias Hidrográficas dos Rios Piracicaba, Capivari e Jundiaí e outras, cuja criação for decidida pelos respectivos Comitês e aprovada pelo Conselho Estadual de Recursos Hídricos.

Em caso de extinção, o patrimônio da Agência será destinado, proporcionalmente, às entidades que comprovadamente houverem contribuído com bens ou recursos financeiros para sua constituição.

\subsection{Minas Gerais - Lei n / $3.199 / 99$}

A Lei n 13.199, de 29/1/99, estabelece a Política Estadual de Recursos Hídricos. Seu art. 37, que dispõe sobre Agências de Bacia, aponta para alternativas que, em função de outras regras contidas no ordenamento jurídico pátrio, inclusive do próprio Estado de Minas Gerais, não podem ser implementadas. Essas normas serão a seguir analisadas, demonstrando, passo a passo, as restrições impostas aos modelos inicialmente autorizados.

$\mathrm{O}$ art. 37 determina que estas entidades, quando instituídas pelo Estado, mediante autorização legislativa, tenham personalidade jurídica própria, autonomia 
financeira e administrativa e organizem-se segundo quaisquer das formas permitidas pelo Direito Administrativo, Civil ou Comercial, atendidas às necessidades regionais, locais e multissetoriais. E estatui que os respectivos atos constitutivos sejam aprovados por meio de Decreto pelo Poder Executivo e devam ser inscritos em registro público $\left(\$ 1^{\circ}\right)$.

Já no caput do artigo apontam-se incongruências. A primeira delas reporta-se "a quaisquer das formas permitidas pelo Direito Administrativo, Civil ou Comercial". Nesse diapasão, seriam, em tese, admitidas as associações, as autarquias, as sociedades comerciais, as sociedades de economia mista, as empresas públicas, as fundaçōes de direito público e fundações de direito privado.

Todavia, o dispositivo menciona que essas entidades sejam instituídas pelo Estado, mediante autorização legislativa, o que reporta à administração pública indireta, cujas figuras admitidas são apenas as autarquias, as empresas públicas, as sociedades de economia mista e as fundações públicas. As fundações de direito privado e as associaçōes ficam excluídas.

Como neste estudo estão sendo consideradas apenas as associações e as fundações, pois trata-se de figuras já previstas nas normas em estudo, há que se descartar a sociedade de economia mista, necessariamente sob a forma de sociedade anônima, em que o lucro é inerente, e, portanto, incompatível com a natureza da Agência. E a empresa pública, que já foi objeto de um estudo anterior na Bacia Hidrográfica, concluindo-se pela não-adoção do modelo.

Restam como figuras permitidas para serem instituídas pelo Estado como Agência de Bacia a autarquia e a fundação pública, podendo esta última, em tese, nos termos da legislação federal, adotar a natureza jurídica de direito público ou de direito privado. Todavia, a Constituição Estadual de Minas Gerais, em seu art. $14, \$ 5^{\circ}$, somente permite ao Estado instituir e manter fundação cuja natureza jurídica seja de direito público, o que equivale, na prática, a uma autarquia.

Restam, assim, a autarquia e a fundação de direito público, figuras em que não é franqueada a participação de entidades da sociedade civil nos respectivos conselhos gestores, levando ao entendimento de que não caberia optar-se por uma figura jurídica instituída pelo Poder Executivo.

Ressalte-se que o dispositivo em referência menciona a condição de instituição pelo Estado. Eventualmente, poderia ser instituída uma Agência por outras pessoas que não o Estado?

A resposta para essa pergunta encontra-se no $\$ 2^{\circ}$ do art. 37 , segundo o qual os consórcios ou as associaçōes intermunicipais de bacias hidrográficas, bem como as associações regionais e multissetoriais de usuários de recursos hídricos, legalmente constituídos, podem ser equiparados às Agências de Bacia, por ato do Conselho Estadual de Recursos Hídricos (CERH-MG), para o exercício de funçōes, competências e atribuições a elas inerentes, a partir de propostas fundamentadas dos comitês de bacias hidrográficas competentes. 
Dessa forma, apenas as associaçōes civis sem fins lucrativos poderiam atuar como Agência das Bacias Hidrográficas dos Rios Piracicaba, Capivari e Jundiaí, tendo em vista que não há previsão legal para as fundações de direito privado, nem como entidades equiparadas às Agências de Bacia.

A lei não distingue entre uma associaçāo já existente ou a ser criada. De qualquer modo, fica aberta a possibilidade para que o Estado de Minas Gerais equipare uma associação civil sem fins lucrativos - consórcio intermunicipal ou associação de usuários - à Agência de Bacia, no que toca ao exercício das suas competências.

O Decreto $\mathrm{n}^{\mathrm{0}} 41.578$, de $8 / 3 / 01$, que regulamenta a Lei $\mathrm{n}^{0} 13.199 / 97$, determina, em seu art. 19, que o CERH-MG regulamente as Agências de Bacia Hidrográfica e entidades a elas equiparadas, observado o seguinte: 1 . a água é um bem de domínio público, cujo acesso é universal; 2 o caráter técnico de sua atuação; 3. a necessidade de constituir-se em uma estrutura gerencialmente compatível e eficiente e 4. a sua vinculação efetiva aos órgãos do Sistema Estadual de Gerenciamento de Recursos Hídricos (SEGRH-MG) para integração das ações.

No que se refere ao controle, o parágrafo único dispōe que as Agências de Bacia Hidrográfica devem apresentar, semestralmente, ao respectivo Comitê, os balanços de aplicação dos recursos financeiros.

A proposta de criação de consórcio ou de associação intermunicipal de bacia hidrográfica ou de associação regional, local ou multissetorial de usuários de recursos hídricos dá-se mediante livre iniciativa dos municípios, devidamente autorizados pelas respectivas Câmaras Municipais, ou mediante livre manifestação de usuários de recursos hídricos (art. 39).

Nos termos do art. 38, as Agências de Bacia ou as entidades a elas equiparadas, por ato do CERH-MG, atuam como unidades executivas descentralizadas de apoio aos respectivos Comitês de Bacia Hidrográfica e respondem pelo seu suporte administrativo, técnico e financeiro, e pela cobrança pelo uso dos recursos hídricos, na sua área de atuação.

A Agência de Bacia Hidrográfica tem a mesma área de atuação de um ou mais comitês de bacia hidrográfica e sua criação é autorizada pelo CERH-MG mediante solicitação de um ou mais comitês (art. 44).

O longo rol de competências da Agência de Bacia ou entidades a ela equiparadas em sua área de atuaçāo está definido no art. 45, e refere-se a: 1. balanço atualizado da disponibilidade hídrica; 2 . cadastro de usos e de usuários e gestão do Sistema de Informações sobre Recursos Hídricos; 3. Plano Diretor e Projetos Emergenciais de Controle da Quantidade e da Qualidade dos Recursos Hídricos; 4. monitoramento da quantidade e da qualidade das águas; 5. relatórios sobre a situação dos recursos hídricos; 6 . cobrança; 7 . pareceres sobre projetos e obras a serem financiados com recursos da cobrança; 8. administração financeira dos valores arrecadados com a cobrança; 9 . análise de projetos e obras considerados 
relevantes para encaminhamento às instituiçōes responsáveis por seu financiamento, implantação e implementação; 10 . análise de pedidos de financiamento, relacionados com recursos hídricos; 11 . proposta do plano de aplicação dos recursos financeiros arrecadados com a cobrança; 12. gestão dos recursos financeiros gerados pela cobrança por meio de instituição financeira; 13 . proposta de enquadramento dos corpos de água nas classes de uso, dos valores a serem cobrados pelo uso de recursos hídricos e do plano de aplicação dos valores arrecadados com a cobrança; 14. apoio administrativo, técnico e financeiro ao comitê.

O Decreto $\mathrm{n}^{\circ} 44.046$, de $13 / 6 / 05$, regulamenta a cobrança pelo uso de recursos hídricos no Estado de Minas Gerais. No processo de efetivação da cobrança, às Agências de Bacia cabem as atribuiçōes ali definidas, conforme explicitado a seguir. De plano, o Decreto menciona que tais competências devem ser exercidas pelas Agências de Bacia Hidrográfica ou entidades a ela equiparadas, sendo que, na sua falta, elas ficam reservadas ao Instituto Mineiro de Gestāo de Águas (IGAM).

Nos termos do art. $5^{\circ}$, a cobrança condiciona-se, entre outros, à instituição de Agência de Bacia Hidrográfica ou entidade a ela equiparada, na mesma área de atuação de um ou mais comitês de bacia hidrográfica (inciso II).

À Agência de Bacia Hidrográfica ou entidades a ela equiparadas e, na sua falta, ao IGAM, compete elaborar estudos financeiros, jurídicos e técnicos para fundamentar a análise da proposta de cobrança, incluindo os valores a serem cobrados pelo uso da água. Ou seja, para servir de apoio à decisão do respectivo comitê, no âmbito das etapas definidas para a implantação da cobrança em cada bacia hidrográfica. Tais estudos têm como base os mecanismos e quantitativos já sugeridos pelo comitê de bacia hidrográfica (art. $5^{\circ}, \mathbb{3} 3^{\circ}$ ).

Enquanto não forem estabelecidos os critérios de cobrança, a Agência de Bacia Hidrográfica ou entidades a ela equiparadas e, na sua falta, o IGAM, podem, mediante expressa autorização dos comitês de bacias hidrográficas, celebrar convênio, termo de ajuste ou outro instrumento congênere com entidades públicas e privadas usuárias de águas das respectivas bacias para 1. cessão de equipamentos, recursos materiais e humanos; 2 . realização de trabalhos e 3. viabilizar ações imediatas que possibilitem, direta ou indiretamente, a melhoria das coleções hídricas, de forma compativel com os planos de ação e diretrizes estabelecidos pelo referido comitê de bacia hidrográfica (art. $8^{\circ}$ ). Tais ações, devidamente traduzidas em expressão monetária, devem ser contabilizadas pelo IGAM como antecipação de pagamento pelo uso de recursos hídricos em nome do comitê beneficiado e lançadas a crédito do usuário.

Cabe ainda à Agência de Bacia Hidrográfica ou entidades a ela equiparadas e, na sua falta, ao IGAM, apresentar, anualmente, ao respectivo comitê de bacia hidrográfica, relatórios demonstrativos da contabilização dos valores apurados no que se refere à sistemática acima mencionada.

A Agência de Bacia Hidrográfica e as entidades a ela equiparadas têm ainda a atribuição de recomendar a aplicação dos valores arrecadados com a cobrança em 
projetos e obras que alterem a qualidade e quantidade e o regime de vazão de um corpo de água, considerados benéficos para a coletividade pelo respectivo comitê de bacia hidrográfica, cabendo a estes definir o montante máximo de recursos a serem aplicados a fundo perdido. É o que dispōe o art. 15.

Devem as Agências de Bacia Hidrográfica e as entidades a elas equiparadas ou, em sua falta, o Instituto Mineiro de Gestão de Águas (IGAM), encaminhar anualmente ao CERH-MG, para apreciaçāo e aprovação final, relatório já devidamente aprovado pelos respectivos Comitês, demonstrando o balanço das arrecadaçōes e das aplicações financeiras em suas áreas de atuação, e sua conformidade com os planos de aplicação dos valores arrecadados com a cobrança pelo uso de recursos hídricos de que trata a alínea $c$ do inciso XII do art. 45 da Lei $n^{9} 13.199$, de 1999.

Nos termos do art. 18, os procedimentos administrativos para a cobrança pelo uso de recursos hídricos devem ser realizados pelas Agências de Bacias Hidrográficas ou entidades a elas equiparadas, por delegaçāo do IGAM, após o cumprimento de todas as condicionantes relativas às etapas de implantação, conforme fixado nos arts. $5^{\text {o10 }}$ e $6^{\text {o11 }}$ do Decreto.

Cabe ainda ao IGAM apoiar as ações das Agências de Bacias Hidrográficas ou entidades a elas equiparadas junto às demais entidades de governo nos processos administrativos e judiciais relativos à aplicação da cobrança pelo uso de recursos hídricos, nos termos do art. 19, III.

Na sistemática dotada no Decreto em questão (art. 19, VIII), o IGAM deve arrecadar os recursos obtidos com a cobrança pelo uso dos recursos hídricos para repasse, integral e imediatamente, às Agências de Bacias e entidades a elas equiparadas, mediante convênio ou instrumento contratual congênere. Nos casos em que não houver legalmente constituída Agência de Bacia ou entidade a ela equiparada, o IGAM deve aplicar diretamente os recursos obtidos com a cobrança pelo uso dos recursos hídricos (art. 19, parágrafo único).

\section{Considerações acerca das condicionantes jurídicas para adoção de uma única agência}

A premissa do estudo foi a instituição de uma única Agência das Bacias Hidrográficas dos Rios Piracicaba, Capivari e Jundiaí para desempenhar funções pe-

\footnotetext{
10 I - definição dos usos insignificantes pelo respectivo comitê de bacia hidrográfica; II - instituição de agência de bacia hidrográfica ou entidade a ela equiparada, na mesma área de atuação de um ou mais comitês de bacia hidrográfica e III - aprovação pelo CERH-MG da proposta de cobrança, tecnicamente fundamentada, encaminhada pelo respectivo comitê de bacia hidrográfica.

11 A cobrança pelo uso de recursos hídricos somente poderá ser iniciada pelo princípio da tarifação progressiva, previsto no art. $43, \$ 3^{2}$, do Decreto $n^{2} 41.578$, de 2001 , se cumprido o disposto nos incisos I, II e III do art. $5^{\circ}$ e nos incisos do art. 53 da Lei $n^{\circ} 13.199$, de 1999.
} 
rante a União, por intermédio da ANA e os Estados de São Paulo e Minas Gerais. Para tanto, a figura jurídica adotada deveria ser compativel com os respectivos ordenamentos jurídicos.

A partir da análise efetuada sobre Agências, à luz 1. das figuras jurídicas previstas na legislação brasileira, entendidas como passíveis de constituir Agências de Bacia ou Agências de Água e 2. das normas em vigor sobre as políticas e sistemas de gerenciamento de recursos hídricos, que fixam as regras para a criação e funcionamento dessas entidades, algumas consideraçōes foram efetuadas, antes de se partir para uma proposta.

Tanto a Política Nacional como a Política de Minas Gerais de Recursos Hídricos permitem dois modelos para as Agências: 1. a Agência propriamente dita, instituída especificamente para tanto e 2 . a adoção de outras entidades de direito privado, existentes ou a serem criadas especificamente, que recebem delegação do detentor do domínio dos recursos hídricos, para assumir as funçōes das Agências.

Nesse último caso, a entidade de direito privado não pode efetuar a cobrança (no sentido de arrecadar) pelo uso de recursos hídricos, tendo em vista tratar-se de recursos públicos.

Já no Estado de São Paulo, o modelo institucional adotado é mais rígido, pois restringe a figura da Agência de Bacia a uma fundação de direito privado, em que o Poder Executivo Estadual participa da respectiva constituição.

\section{Alternativas}

Com as observaçōes acima efetuadas, as alternativas de modelo institucional da Agência das Bacias Hidrográficas dos Rios Piracicaba, Capivari e Jundiaí restringiram-se a duas: 1 . fundação de direito privado e 2 . associação civil sem fins lucrativos.

Cabe detalhar, nesse passo, as vantagens e desvantagens de cada alternativa, indicando-se eventual necessidade de alteração das normas legais em vigor, com vistas à observância da premissa do estudo, que consiste em uma Agência única para a região hidrográfica.

\section{Alternativa 1 - Fundação de direito privado}

Trata-se a fundação de um acervo de bens - patrimônio - que recebe personalidade para realizar uma certa finalidade. ${ }^{12} \mathrm{O}$ patrimônio se personaliza quando a fundação obtém sua existência legal. A constituição da fundação só ocorre no ato de personificação, não bastando a destinação de bens.

12 "Para criar uma fundação, far-lhe-á o seu instituidor, por escritura pública [...], dotação especial de bens livres, especificando o fim a que se destina, e declarando, se quiser, a maneira de administrá-la." (Código Civil, art. 62). 
O âmbito de atuação das fundações restringe-se a fins religiosos, morais, culturais ou de assistência, finalidades que se amoldam à origem histórica dessas instituições (art. 62, parágrafo único). Em face dessa restrição, caberia indagar se uma Agência de Bacia, com atividades relacionadas com a gestão dos recursos hídricos, poderia constituir uma fundação.

Essa dúvida encontra-se no momento superada, pois, nos termos do Enunciado 8 do Centro de Estudos Judiciários do Conselho da Justiça Federal, órgão vinculado ao Superior Tribunal de Justiça, incluem-se nesse parágrafo único os fins científicos, educacionais ou de promoção do meio ambiente. ${ }^{13}$ Nesse caso, é possível a interpretação de que a Agência de Bacia, assim como todo o Sistema de Gerenciamento de Recursos Hídricos, tem por finalidade a melhoria dos aspectos qualitativos e quantitativos dos recursos hídricos, enquadrando-se nas finalidades voltadas à proteção ambiental.

$\mathrm{Na}$ constituição da fundação, existem dois momentos básicos: 1. o ato de fundação propriamente dito, que é sua constituição emanada de vontade dos instituidores e 2. o ato de dotação de um patrimônio, que lhe dá vida. O patrimônio é elemento essencial para as fundações, ao contrário do que ocorre com as demais pessoas jurídicas. Nas fundaçōes, os fins não podem ser modificados porque são fixados pelo instituidor, enquanto em outras figuras jurídicas é possível alterar a finalidade social.

A instituição é regida por seus estatutos, sempre sob a fiscalização do Ministério Público. Em geral, institui-se um Conselho de Administração, cujo presidente representa a entidade, podendo instituir-se, também, de acordo com a necessidade, um Conselho Executivo, um Conselho Fiscal e outros órgãos colegiados.

A fundação de direito privado é o modelo institucional definido pelo Estado de São Paulo, na Lei no 10.020/98. Evidentemente, é adequado à legislação paulista. Cabe verificar compatibilidade dessa entidade com as normas federais e as de Minas Gerais.

Considerando que a cobrança já foi implantada nos rios de domínio da União, e tendo em vista que a Lei $n^{\circ} 10.881 / 04$ prevê a possibilidade de celebração de contrato de gestão entre a Agência Nacional de Águas (ANA) e as organizações civis de recursos hídricos previstas no art. 47 da Lei nº 9.433/97, entende-se que a

13 O Centro de Estudos Judiciários (CEJ), órgāo do Conselho da Justiça Federal (CJF), tem a atribuiçāo de desenvolver estudos, pesquisas e serviços de informação jurídica para o aperfeiçoamento do Sistema Judiciário. Suas atividades objetivam, basicamente, a atualizaçāo e a ampliação de conhecimentos, o incentivo à pesquisa e o intercâmbio de idéias, permitindo que o Conselho da Justiça Federal atenda à finalidade prevista no parágrafo único do art. 105, da Constituição Federal, qual seja atuar, junto ao Superior Tribunal de Justiça (STJ), supervisionando a Justiça Federal de $1^{\circ}$ e $2^{\circ}$ graus. No exercício de suas atribuições, o CEJ aprovou uma série de enunciados, durante a Jornada de Direito Civil, em setembro de 2002, tendo por objeto a interpretaçāo dos dispositivos do Novo Código Civil, dentre os quais o Enunciado 8, com a seguinte redação: "A constituição de fundação para fins científicos, educacionais ou de promoçāo do meio ambiente está compreendida no Código Civil, artigo 62, parágrafo único." 
fundação de direito privado insere-se no disposto no inciso V, que admite "outras organizações reconhecidas pelo Conselho Nacional ou pelos Conselhos Estaduais de Recursos Hídricos".

A dificuldade que se impõe, nesse modelo, refere-se ao Estado de Minas Gerais, pois a Lei n 13.199/97 admite apenas "os consórcios ou as associaçōes intermunicipais de bacias hidrográficas, bem como as associaçōes regionais e multissetoriais de usuários de recursos hídricos, legalmente constituídos", como passíveis de equiparação às Agências de Bacia, por ato do CERH-MG, para o exercício de funções, competências e atribuições a elas inerentes, a partir de propostas fundamentadas dos comitês de bacias hidrográficas competentes (art. $37, \$ 2^{\circ}$ ).

A única forma de viabilizar o modelo da fundação de direito privado como entidade única nas bacias hidrográficas seria a inclusão da fundação de direito privado no rol de entidades que podem ser equiparadas à Agência de Bacia. Nessa hipótese, deve ficar claro que o Estado de Minas Gerais, por vedação de sua Constituição Estadual, não participaria da instituição da fundação. Todavia, nada obsta que representantes do Estado participem da gestão da entidade.

A Lei no 10.020/98 não prevê a participação de representantes de outros Estados na gestão da Agência, mas somente da União (art. $3^{\circ}, \$ 1^{\circ}$ ), dispondo que, "no caso da União vir a integrar a Agência e a delegar-lhe ou atribuir-lhe competência para atuar no campo das águas do seu domínio, o número de componentes do Conselho Deliberativo, da Diretoria e do Conselho Fiscal poderá ser alterado, inclusive quanto aos membros permanentes".

Para que o Estado de Minas Gerais possa participar dos Conselhos ou da Diretoria da Agência, cabe acrescentar, no $\$ 1^{\circ}$ do art. $3^{\circ}$ da Lei $n^{\circ} 10.020 / 98$, a participação de Estados que compartilham os recursos hídricos das bacias hidrográficas.

\section{Alternativa 2 - Associação civil sem fins lucrativos}

A Constituição Federal assegura a plena liberdade de associação para fins lícitos, vedada a de caráter paramilitar (art. 5०, XVII). A associação civil sem fins lucrativos é a forma mais flexível para a instituição de uma entidade no direito brasileiro. Regida pelo Código Civil, observa o princípio segundo o qual é permitida a fixação das condiçōes que não estejam limitadas pela lei e em consonância com o ordenamento jurídico pátrio. Qualquer atividade lícita pode ser buscada por uma associação.

Não há, entre os associados, direitos e obrigaçōes recíprocas, mas apenas para com a entidade à qual se associaram (art. 53, parágrafo único). Além dos requisitos essenciais, que devem constar dos estatutos da associação (art. 54), outras disposições podem ser acrescentadas, além das citadas, desde que não conflitem com aquelas obrigatórias, nem com o ordenamento jurídico. 
A assembléia geral é órgão necessário da associação, exercendo função legislativa. A ela compete privativamente destituir os administradores e alterar o estatuto (art. 59), exigida a deliberação da assembléia especialmente convocada para esse fim, cujo quorum é o estabelecido no estatuto, bem como os critérios de eleição dos administradores. A convocação dos órgãos deliberativos faz-se na forma do estatuto, garantido a 1/5 (um quinto) dos associados o direito de promovê-la (art. 60).

A gestão da associação é exercida por um diretor ou uma diretoria, podendo ser criados outros órgãos auxiliares, como conselhos consultivos, fiscais etc.

A associação civil sem fins lucrativos atende perfeitamente à regra fixada na Lei $n^{2}$ 10.881/04, assim como à legislação de Minas Gerais, desde que se trate de consórcio ou associação intermunicipal de bacia hidrográfica, ou de associações regionais e multissetoriais de usuários de recursos hídricos, legalmente constituídos. Todavia, é incompatível com o modelo institucional paulista, conforme já mencionado.

Decidido o início da cobrança nos rios de domínio da União, e no Estado de Minas Gerais, nada impede, sob o aspecto legal, em um primeiro momento e transitoriamente, a qualificação de uma associação, que pode ser, inclusive, o próprio Consórcio Intermunicipal das Bacias Hidrográficas dos Rios Piracicaba, Capivari e Jundiaí, como entidade delegatária para celebrar contrato de gestão com a Agência Nacional de Águas (ANA).

Iniciando-se a cobrança no Estado de Minas Gerais, a associação civil poderia ser equiparada às Agências de Bacia por resolução do Conselho Estadual de Recursos Hídricos (CERH-MG), que deveria detalhar esse procedimento.

Todavia, implantada a cobrança no Estado de São Paulo, a associação, por sua natureza, não poderá transformar-se em fundação. Restou, portanto, criado o impasse para a gestão dos recursos hídricos na Bacia Hidrográfica, com base na premissa de uma Agência única.

$\mathrm{Na}$ linha das alterações legislativas, com vistas a garantir a unicidade da gestão das bacias hidrográficas, cabe vislumbrar a alternativa de modificar a Lei $\mathrm{n}^{\mathrm{o}}$ 10.020/98, que passaria a admitir, também, a possibilidade de delegação, pelo Estado, a uma associação civil sem fins lucrativos, das funçōes de Agência de Bacia.

Nessa hipótese, paralelamente às disposições em vigor da Lei $n^{0} 10.020 / 98$, poderia ser adotada uma sistemática similar àquela objeto da Lei no $10.881 / 04$, nas bacias hidrográficas cujo comitê optasse por essa alternativa. Nesse caso, caberia a cada comitê de bacia hidrográfica definir o modelo de sua Agência.

Cumpre asseverar que cabia uma avaliação aprofundada dessas questões, pois os modelos diferiam na essência: as fundações são entes permanentes, instituídas com a finalidade específica de atuar como Agência de Bacia. Já o modelo que prevê delegação de competências a entidades de direito privado, sem fins lucrativos, atua na linha da contratualização, com a renovação dos respectivos contratos, con- 
dicionada ao cumprimento das metas estabelecidas, podendo haver substituição da entidade delegatária.

Os dois modelos não se excluíam. Juridicamente, era possível admitir essa coexistência. Será necessário verificar, todavia, se institucionalmente cabe essa possibilidade, o que será verificada ao longo do tempo, à medida que forem vivenciadas essas experiências.

\section{Conclusões}

Em face das questōes ora abordadas, concluiu-se que, sendo premissa do estudo a implantação de uma única entidade para constituir a Agência das Bacias Hidrográficas dos Rios Piracicaba, Capivari e Jundiai, tal alternativa somente poderia viabilizar-se mediante a alteração na legislação então vigente.

A questão que se colocou, nesse momento foi a necessidade de dotar os dois Comitês das Bacias Hidrográficas dos Rios Piracicaba, Capivari e Jundiaí de uma estrutura técnica, administrativa e financeira, com personalidade jurídica própria, para operacionalizar as suas deliberaçōes e que viesse a desempenhar funçōes de Agência de Água nas bacias hidrográficas objeto deste estudo.

A alteração de qualquer norma legal, como proposto, demandaria um tempo imponderável. E não se podia aguardar a alteração das normas, para só então ocorrer o início da cobrança. Desejava-se a instituição de uma entidade que, logo de início, pudesse exercer as funçōes definidas para a Agência de Bacia, ou Agência de Águas, na forma das normas em vigor, concomitantemente à implantação da cobrança pelo uso de recursos hídricos.

Coube, então, propor a alternativa julgada mais adequada para o momento, sob a análise relativa muito mais ao cenário político e institucional então vigente nas bacias em apreço do que ao campo jurídico.

A proposta feita consistiu na adoção do Consórcio Intermunicipal das Bacias Hidrográficas dos Rios Piracicaba, Capivari e Jundiaí - Consórcio PCJ - para desempenhar, por prazo determinado, as funções de Agência de Águas nas bacias hidrográficas dos rios Piracicaba, Capivari e Jundiaí. ${ }^{14}$

Sendo associação civil sem fins lucrativos, sua natureza jurídica enquadrava-se nas disposições tanto da legislação federal, como das normas do Estado de Minas Gerais, no que se refere aos recursos hídricos. Tanto a União como o Estado de Minas Gerais já implantaram a cobrança pelo uso de recursos hídricos.

Evidentemente, sob o aspecto legal, outra associação poderia ser adotada para receber delegação do Conselho Nacional de Recursos Hídricos e do Conselho Es-

14 A Resolução CNRH no 53 , de 28/11/05, delegou competência ao Consórcio Intermunicipal das Bacias Hidrográficas dos Rios Piracicaba, Capivari e Jundiai para o exercício de funções inerentes à Agência de Água das Bacias Hidrográficas dos Rios Piracicaba, Capivari e Jundiaí. 
tadual de Recursos Hídricos (CERH-MG). Poderia também ser criada uma nova entidade para tanto.

Todavia, foi consenso nas bacias hidrográficas em apreço que o Consórcio Intermunicipal das Bacias Hidrográficas dos Rios Piracicaba, Capivari e Jundiaí atendia aos requisitos para assumir funções de Agência de Águas previstas nas legislações federal e mineira sobre recursos hídricos. E a criação de uma nova entidade demandaria tempo, o que era indesejável no momento, pelas razões já apontadas.

Dessa forma, ficou temporariamente solucionada a questão. No que se refere ao Estado de São Paulo, conforme já explicitado, a Lei no 12.183, de 29/12/05, regulamentada pelo Decreto $n^{\circ} 50.667$, de 30/03/06, já instituiu a cobrança e busca-se fixar os parâmetros de sua operacionalização. Nesse etapa, deve ser equacionada a questão sobre a alteraçāo da norma que rege as Agências de Bacia no Estado.

A experiência da cobrança dos recursos hídricos de domínio da União nas Bacias Hidrográficas dos Rios Piracicaba, Capivari e Jundiaí está em pleno curso, com índice de adimplência de $98 \%$, cabendo ainda solucionar a questāo legal sobre Agência no Estado de São Paulo, se de fato pretender-se manter o modelo da Agência única.

\section{Referências}

DI PIETRO, Maria Sylvia Zanella. Direito administrativo. 19. ed. São Paulo: Atlas, 2006. GRANZIERA, Maria Luiza Machado. Direito de águas: disciplina jurídica das águas doces. 3. ed. São Paulo: Atlas, 2006.

LAHÓZ, Francisco Carlos Castro; BROCHI, Dalto; RAZERA, Sérgio; TINEL, Paulo; VILELLA, Alexandre. A implantação dos instrumentos de gestão dos recursos hídricos nas bacias $P C J$.

; RAZERA, Sérgio. Estrutura organizacional - metodologia de funcionamento - fluxo financeiro dos recursos da cobrança pelo uso da água e assuntos afins. 33ª Assembléia do Fórum Permanente em Defesa da Bacia do Rio Piracicaba. Piracicaba, SP, 22 dez. 2006. 